\title{
Quality of life in patients with acromegaly vs non-functioning pituitary adenomas and healthy control group.
}

\author{
Authors: Aleksandra Jawiarczyk-Przybyłowska', Dorota Szcześniak², Joanna Rymaszewska², Marek Bolanowski
}

1 Department of Endocrinology, Diabetes and Isotope Therapy, Medical University, Wrocław, Poland

${ }^{2}$ Division of Consultation Psychiatry and Neuroscience, Depatment of Psychiatry Medical University, Wrocław, Poland

\section{OBJECTIVES}

Acromegaly is a rare and chronic illness characterized by changes in the appearance and functioning of the internal organs in the affected person.

Acromegaly has an important impact on health-related quality of life. The aim of study was to ascertain the quality of life of patients with uncontrolled vs controlled acromegaly and compared to those with non-functioning adenomas and healthy control group.
METHODS

124 participants underwent a cross-sectional assessment including the quality of life (AcroQoL, WHOQoL BREF), psychiatric morbidity (GHQ-28) and acceptance of illness (AIS). The sample consists of patients with acromegaly (AG) divided into two subgroups accordingly to minimal GH concentration during the OGTT or profile of $\mathrm{GH}$ and level of IGF-1: controlled and cured acromegaly group (CAG $n=19$ ) and active acromegaly group (AAG $n=31$ ); patients with non-functioning adenomas group (NFG $n=37$ ) and healthy control group (CG $n=37$ ) matched according to age.

\begin{tabular}{|c|c|c|c|c|c|c|}
\hline \multicolumn{3}{|c|}{$\begin{array}{l}\text { Table 1. General characteristics of acromegaly } \\
\text { (AG) and non-functioning groups (NFG). }\end{array}$} & \multicolumn{4}{|c|}{$\begin{array}{l}\text { Table 2. The frequence of some symptoms in } \\
\text { acromegaly (AG) and non-functioning groups (NFG). }\end{array}$} \\
\hline Factor & Mean $\pm S D(A G)$ & $\begin{array}{l}\text { Mean } \pm \text { SD } \\
\quad(N F G)\end{array}$ & Symptoms & $A G(n=50)$ & $\begin{array}{l}\text { NFG }(n= \\
\quad 37)\end{array}$ & $\mathbf{P}$ \\
\hline \multirow{3}{*}{ Age } & & & Headache & $33(66 \%)$ & $23(62 \%)$ & $<0.88$ \\
\hline & $\begin{array}{c}51.7 \\
\pm 14.5\end{array}$ & $\begin{array}{c}48.9 \\
\pm 15.12\end{array}$ & Decreased libido & $18(36 \%)$ & $10(27 \%)$ & $<0.67$ \\
\hline & & & Joint pain & $34(68 \%)$ & $13(35 \%)$ & $<0.003$ \\
\hline \multirow[t]{2}{*}{$\operatorname{Sex}(F \%)$} & $62 \%$ & $72 \%$ & Sweating & 38 (76\%) & $14(17 \%)$ & $<0.001$ \\
\hline & & & Changes in facial & $43(86 \%)$ & 0 & $<0.000$ \\
\hline \multirow{2}{*}{$\begin{array}{c}\text { Illness duration } \\
\text { since diagnosis } \\
\quad \text { (years) }\end{array}$} & $\begin{array}{r}4.5 \\
\pm 1.5\end{array}$ & $\begin{aligned} & 2.9 \\
\pm & 2.01\end{aligned}$ & $\begin{array}{l}\text { Visual field } \\
\text { disturbances }\end{array}$ & 27 (54\%) & $19(51 \%)$ & $<0.1$ \\
\hline & & & Galactorrhoea & $4(8 \%)$ & $8(21 \%)$ & $<0.04$ \\
\hline
\end{tabular}

\section{RESULTS}

No significant differences were identified between CAG, AAG and NAG groups referring to quality of life, psychiatric morbidity and acceptance of illness. Compared with healthy controls, AAG group suffered more from anxiety and insomnia $(p=0.031)$ and had significantly poorer quality of life in psychological domain measured with WHOQoL BREF $(p=0.004)$. The average AcroQoL score was $56.72 \pm 16.03$, with the mean physical dimension score of $53.81 \pm 19.99$ and mean psychological dimension of $58.21 \pm 15.59$. The lowest score was noted in subscale "appearance" $45.28 \pm 19.91$ and the highest in subscale "personal relations" $71.28 \pm 16.54$. In acromegaly group we observed statistically significant positive correlation between the level of IGF-1 and prevalence of psychopathological symptoms measured by the GHO28. We also observed negative correlation with the level of $\mathrm{GH}$ and AcroQoL in total score as well as in psychological dimension, including subscale "appearance". The illness duration since diagnosis was identified as a negative predictor of physical dimension of AcroQoL ( $r=-0.35, p=0.035)$, social domain of WHOQoL $(r=-0.43, p=0.009)$ and acceptance of the illness $(r=-0.42, p=0.011)$. In acromegaly group we also observed statistically significant positive correlation AIS with AcroQoL $(r=0.66, p<0.000)$ and negative correlation with GHQ-28 $(r=-0.36, p<0.009)$.

\section{CONCLUSIONS}

\section{References}

1. Concerning the diagnosis, not only biochemical and radiological parameters, but also psychological aspect should be evaluated in acromegaly.

2. The coexistence of psychopathological symptoms has impact on the quality of life, as well as on the acceptance of the disease.

3. The higher acceptance of illness, the better quality of life is observed in acromegaly.

4. There is no difference in psychosocial perspective between patients with acromegaly and non-functioning adenomas in the present study group.

5. IGF-1 and GH could be an independent negative predictors of quality of life among those acromegaly. J Clin Endocrinol Metab 2004; 89: 667-674, 2. Webb S M, Badia X: Quality of Life in Growth Hormone Deficiency and Acromegaly. Endocrinol Metab Clin N Am. 2007; 36: 221-232 3. Melmed S, Casanueva FF, Klibanski A, Bronstein MD, Chanson P, Lamberts SW, Strasburger CJ, Wass JAH, Giustina A, A consensus on the diagnosis and the treatment of acromegaly, Pituitary, 2012, published online. 